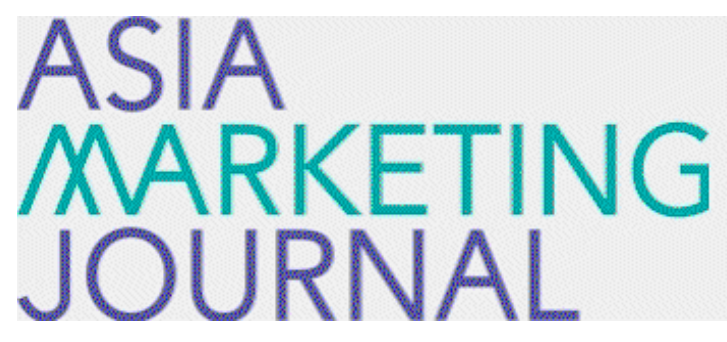

ASIA MARKETING JOURNAL

Volume 19 | Issue 3

Article 1

10-31-2017

\title{
Overcoming the Cause Marketing Paradox
}

Shinhyoung Lee

Youjae Yi

Follow this and additional works at: https://amj.kma.re.kr/journal

Part of the Marketing Commons

\section{Recommended Citation}

Lee, Shinhyoung and Yi, Youjae (2017) "Overcoming the Cause Marketing Paradox," Asia Marketing Journal: Vol. 19 : Iss. 3 , Article 1.

Available at: https://doi.org/10.15830/amj.2017.19.3.1

This Article is brought to you for free and open access by Asia Marketing Journal. It has been accepted for inclusion in Asia Marketing Journal by an authorized editor of Asia Marketing Journal. 


\title{
Overcoming the Cause Marketing Paradox: The Effect of Nostalgia on Charitable Giving and Happiness*
}

\author{
Shinhyoung Lee** \\ Youjae $\mathrm{Yi}^{* * *}$
}

\begin{abstract}
The current research examines whether and when cause marketing, whereby firms link product sales to the support of a charity or cause, can increase charitable giving and happiness. Previous research suggests that cause marketing might reduce charitable giving and happiness among consumers. However, the present research finds the opposite result by introducing nostalgia as a moderator; cause marketing can enhance consumers' charity giving when their nostalgia is triggered. Moreover, results show that charitable giving increased by cause marketing improves feelings of happiness, suggesting that people view charitable behavior as a means of enhancing happiness. Interestingly, charitable giving and happiness are promoted by the situational priming of nostalgic events, but not by chronic individual differences such as nostalgia proneness.
\end{abstract}

Key words: cause marketing, cause marketing paradox, nostalgia, charitable giving, happiness

\section{Introduction}

TOMS is not only known as a brand that provides comfortable and fashionable shoes, eyewear, and apparels, but also famous for its business model based on cause marketing. Under the slogan "one for one," TOMS promises "with every product you purchase, TOMS will help a person in need." It means that when a consumer buys a pair of shoes at TOMS, the company gives a pair of shoes to a child in developing countries. Then, a question might arise. If a consumer who has participated in a cause by purchasing items at TOMS were subsequently invited to donate to a charity, what would the consumer's donation intention be?

Cause marketing or cause-related marketing

\footnotetext{
* This research was supported by the Institute of Management Research, Seoul National University

** Doctoral Candidate, College of Business Administration, Seoul National University (shinny11@gmail.com)

*** Professor of Marketing, College of Business Administration, Seoul National University (youjae@snu.ac.kr), Corresponding Author
} 
(CM) links "product sales to support of a charity or cause" (Varadarajan \& Menon, 1988; cited in Robinson, Irmak, \& Jayachandran, 2012, p. 126). Numerous firms adopt cause marketing today so as not only to improve sales performance but also to promote charitable activities. In this sense, although people regard cause marketing as one type of corporate social responsibility (CSR), it is distinct from many other charitable activities such as direct donations involving obvious costs. Since consumers obtain a product in return for participating in cause marketing, this prosocial behavior can be regarded as a form of "shopping" rather than pure "giving."

Drawing on this characteristic of cause marketing, prior research investigated how cause marketing affects individuals' subsequent donations. Contrary to general beliefs or expectations, Krishna (2011) suggests that purchasing a CM product can decrease subsequent donations from individuals. This phenomenon is explained by the view that the motive for participating in cause marketing activates egoistic altruism rather than empathetic altruism, negatively affecting direct donations and happiness. According to the literature on the motivation for prosocial behavior (Batson \& Shaw, 1991; Cialdini et al., 1987), egoistic (selfish) altruism and empathetic (selfless) altruism are different in terms of their intended goals. Egoistic altruism regards helping behavior as a means for the ultimate goal of self-benefit, whereas empathetic altruism treats helping others as an ultimate goal rather than as a means of gaining ones' own interest. Since supporting cause marketing provides some tangible benefits to the consumer in return, cause marketing is likely to trigger egoistic altruism that makes individuals focus more on self-benefit and self-utility (Krishna, 2011).

This counterintuitive finding has important implications for corporations implementing cause marketing as a way of fulfilling CSR. Prior research (Krishna, 2011) shows that cause marketing can be non-conducive to making donations and a shot at happiness. Then, a question arises. Does cause marketing always decrease direct donations from individuals? If not, when would cause marketing render a positive effect on subsequent charitable giving? We wish to explore a specific condition in which cause marketing can increase donations. In this research, we introduce nostalgia, "a personally experienced and valued past" (Zhou, Wildschut, Sedikides, Shi, \& Feng, 2011, p. 39 ), as a moderating variable of the cause marketing-charity giving relationship. This framework is inspired by the prior research (Zhou et al., 2011) showing that nostalgia can promote individuals' intentions to donate to charity. Feeling nostalgic reminds one of significant others in close relationships and further strengthens a sense of social connectedness (Wildschut, Sedikides, Arndt, \& Routledge, 2006: Zhou, Sedikides, Wildschut, \& Gao, 2008). Thus, recalling nostalgic memories can increase 
one's willingness to help others (Zhou et al., 2011). We can further expect that cause marketing for nostalgic products (as opposed to contemporary products) may increase subsequent charity giving and happiness. Since the consumption of a nostalgic product can help restore one's feeling of belongingness and enhance a sense of social connection (Loveland, Smeesters, \& Mandel, 2010), we propose that if nostalgic elements are added to the CM product, they would positively change the impact of cause marketing on subsequent charity giving and happiness.

The purpose of this article is to investigate how we overcome the cause marketing paradox (Krishna, 2011), hypothesizing that cause marketing can increase subsequent donations and happiness when consumers are primed with nostalgia. In addition, since individuals have chronic differences in the degree of engaging in nostalgic recollections, this research also examines the role of nostalgia proneness. The remainder of the article describes a more detailed theoretical background, specific hypotheses, and the empirical work to test our proposition.

\section{Theoretical Background}

\subsection{Cause Marketing Paradox}

Cause marketing or cause-related marketing $(\mathrm{CM})$ is defined as "the process of formulating and implementing marketing activities that are characterized by an offer from the firm to contribute a specified amount to a designated cause when customers engage in revenueproviding exchanges that satisfy organizational and individual objectives" (Varadarajan \& Menon, 1988, p. 60). Based on the definition above, we distinguish the notion of cause marketing from other types of firms' charitable behavior (e.g., philanthropy), focusing on the attribution of revenue-providing exchanges via purchase of products. This means that, for consumers who purchase a CM product, supporting a cause can be perceived as costless, since they gain the product in need anyway in return for their participation in cause marketing. On the contrary, if consumers support other forms of prosocial behavior such as expenseincurring giving, they may be reluctant to donate to subsequent charity events.

However, prior research (Krishna, 2011) demonstrates that cause marketing purchase may reduce total charitable donations from consumers, even if supporting a cause is costless to the consumers and thereby has no effect on their mental donation budget. That is, 'firm contribution + individual direct donation' decreases direct donations from individuals, which in turn lowers the total donation amount raised for the cause, contrary to our lay beliefs. Moreover, Krishna (2011) suggests that CM purchase has a potential to reduce consumer happiness if consumers substitute charitable 
giving for cause marketing. In this way, cause marketing and direct donations can be two sides of the same coin, even if they both have a good cause.

To investigate the reasons of these phenomena, we need to look into different aspects of altruistic behavior. Prior studies report that the motivations for prosocial behaviors are composed of two types of altruism: selfish (egoistic) and selfless (empathetic) altruism. Cialdini et al. (1987) suggest the Negative State Relief model by interpreting the motive of helping behavior as an egoistic desire to relieve the sadness of observers rather than that of sufferers. In contrast, Batson (1987) proposes the EmpathyAltruism model by viewing the helping motive as the purely selfless giving guided by an empathic orientation. Taken together, researchers have concluded that there are two types of motivation and goal behind prosocial behaviors (Batson \& Shaw, 1991): egoistic (or selfish) altruism that benefits the donor and empathetic (or selfless) altruism that primarily benefits the recipient. The former approach regards the ultimate goal of prosocial acts as self-benefit, with helping others being an instrumental goal. In contrast, the latter approach regards the ultimate goal of prosocial acts as helping itself, with self-benefit being an unexpected outcome (Batson \& Shaw, 1991). Since supporting cause marketing inevitably entails the acquisition of a product, cause marketing highlights the nuance of egoistic altruism rather than empathetic altruism. That is to say, consumers purchasing the CM product might have their own interests and utilities in mind, whereas consumers participating in direct donation cannot expect tangible benefits in return. Based on this explanation, prior research suggests the cause marketing paradox (Krishna, 2011), indicating that consumers recognize that their motives are inherently more selfish for cause marketing than for other forms of charitable giving, which in turn decreases subsequent charitable donations and happiness.

Recent investigations in various consumer contexts support the cause marketing paradox. Khan and Dhar (2006) propose that commitment to an altruistic act in a preceding choice can boost a positive self-concept and thus liberate people to choose a more self-indulgent option in subsequent choice. Sachdeva, Iliev, and Medin (2009) suggest that enhancing moral self-worth leads people to feel licensed to behave immorally. Mazar and Zhong (2010) provide evidence that the purchase of green products licenses indulgence in unethical and less altruistic behavior. Beyond the literature on moral regulation and licensing effect, studies directly related to cause marketing indicate the similar effect. Flaherty and Diamond (1999) argue that consumers who purchase products on cause marketing may feel that they have fulfilled their philanthropic obligations, and thus tend not to donate on later occasions. Lichtenstein, Drumwright, and Braig (2004) suggest that 
supporting charitable causes via CSR programs may decrease individuals' direct donations. In conjunction with these findings, Krishna (2011) explains that consumers may mentally allocate expenditures for cause marketing as charitable giving, eliciting the lower level of philanthropic intentions for subsequent charitable acts. Since her research did not incur any additional cost for supporting a cause, the former activities should not affect consumers' mental donation budgets. However, once egoistic altruism is activated by purchasing a CM product, consumers might be indulged in self-centered activities and feel licensed to cut their donation budgets. All these arguments comprehensively strengthen the proposition of the cause marketing paradox, indicating that cause marketing reduces consumers' direct philanthropy to subsequent charities and thereby total donations raised for the cause.

In terms of the relationship between prosocial behavior and happiness, researchers have shown that charitable behavior enhances the giver's feeling of happiness. Dunn, Aknin, and Norton (2008) find that "spending more of one's income on others predicted greater happiness (p. 1687).” Liu and Aaker (2008) suggest that spending time for charity, which evokes an emotional mind-set, can be a means toward personal happiness, whereas spending money for charity, which evokes a value-maximizing mind-set, can attenuate the giving - happiness relationship. Krishna (2011) interprets the link between charitable giving and happiness as a function of egoistic versus empathetic altruism: namely, substituting cause marketing for direct donation results in lower happiness, facilitating the selfbenefit and self-utility. Taken together, while the pattern of donor's happiness can be predicted in the same way as charitable giving, whether the relationship moves in a positive or negative direction would be determined by the types and/or characteristics of charitable activities.

\subsection{Nostalgia and Charitable Giving}

Nostalgia is defined as "a sentimental longing for a personally experienced and valued past" (Sedikides, Wildschut, \& Baden, 2004; cited in Zhou et al., 2011, p. 39). As a social emotion, nostalgic episodes evoke interactions with significant others (Holak \& Havlena, 1992), entailing the recollection of momentous life events such as childhoods, graduations, and anniversaries (Wildschut et al., 2006). Therefore, nostalgia makes one reestablish a symbolic connection with close others (Sedikides, Wildschut, Arndt, \& Routledge, 2006; Sedikides et al., 2004) and this bolstered social bond affords one's need to belong, thus benefiting self-esteem and a sense of safety and security (Leary \& Baumeister, 2000; Mikulincer, Florian, \& Hirschberger, 2003).

The social function of nostalgia has been treated importantly in many studies. Baumeister and Leary's (1995) research on the need to belong confirms the strong link between nostalgia 
and social connectedness. The need to belong not only predicts one's experience of nostalgia but also increases nostalgic propensity (Seehusen et al., 2013). Wildschut et al. (2006) empirically investigate whether nostalgia strengthens social bonds and generates positive affect by reigniting meaningful relationships. Moreover, nostalgia reduces one's loneliness by imbuing social connectedness (Zhou et al., 2008). In sum, feeling socially disconnected generates desire for nostalgia, whereas feeling nostalgic fosters social connectedness. Hence, social connectedness works as both a key consequence and an antecedent of nostalgia (Lasaleta, Sedikides, \& Vohs, 2014; Seehusen et al., 2013). All these arguments support the major function of nostalgia reinforcing relational bonds.

Extending the above arguments to the domain of helping behavior, some research has suggested that a sense of social connectedness increases prosocial behavior. Mikulincer, Shaver, Gillath, and Nitzberg (2005) show that the primed attachment security entails greater compassion toward distressed people and more altruistic behavior. Zhou et al. (2011) examine whether nostalgia promotes prosocial behavior such as charity donations and tangible giving. They also find that the mechanism behind the relationship between nostalgia and charitable giving is empathy, not personal distress from witnessing others' suffering. In other words, nostalgia strengthens individuals' intentions to contribute to charity (e.g., helping, volunteering, and donating; Stephan et al., 2014); more importantly, empathy mediates the effect of nostalgia on charitable giving.

\section{Hypotheses}

This study examines how nostalgia influences the effect of cause marketing on subsequent charitable giving and happiness. Nostalgia is regarded as a preference for things from the past and defined as "a preference (general liking, positive attitude, or favorable affect) toward objects (people, places, or things) that were more common (popular, fashionable, or widely circulated) when one was younger (in early adulthood, in adolescence, in childhood, or even before birth)" (Holbrook \& Schindler, 1991, p. 330; 2003, p. 108). According to this conceptualization, nostalgia can be represented by nostalgic things or products above all other recollected vehicles such as people and places.

Since nostalgia promotes charitable intention and tangible giving (Zhou et al., 2011), if someone purchases nostalgic products to participate in cause marketing, he/she will probably not be as parsimonious to donation as a person who purchases contemporary products. Furthermore, we predict that participation in cause marketing (vs. no-CM) under the nostalgia condition leads to higher subsequent charitable giving and happiness. We suggest this prediction 
based on the memory marker model, a model of consumers' memory for experiences (Ahn, Liu, \& Soman, 2009). Similar to Kundera (1999)'s view that "memory does not make films, it makes photographs," Ahn et al. (2009) propose that the human brain generates mental memory markers of the environment when there are cognitive or sensory changes that occur around us. Therefore, these memory markers allow quick and easy recollection of rich experiences especially characterized by vivid stimuli even after a period. Building on this research, we predict that nostalgic episodes represented as tangible products (in the CM condition) can work as a function of memory marker which serves to make nostalgic moments become more vivid and longer in duration. Thus, the expectation is that:

H1: Under the nostalgia condition, (a) cause marketing (vs. no-CM) has a positive effect on charitable giving.

(b) cause marketing (vs. no-CM) has a positive effect on happiness.

On the other hand, previous literature (Krishna, 2011) shows that participating in cause marketing triggers egoistic altruism that reduces subsequent charitable giving and happiness. Thus, the following hypothesis is proposed:

H2: Under the control condition,

(a) cause marketing (vs. no-CM) has little (or a negative) effect on charitable giving.

(b) cause marketing (vs. no-CM) has little (or a negative) effect on happiness.

Drawing from the previous research, we expect to observe that those two dependent variables (i.e., charitable giving and happiness)

〈Figure 1〉 Conceptual model for the interaction effect of cause marketing and nostalgia on charitable giving and happiness

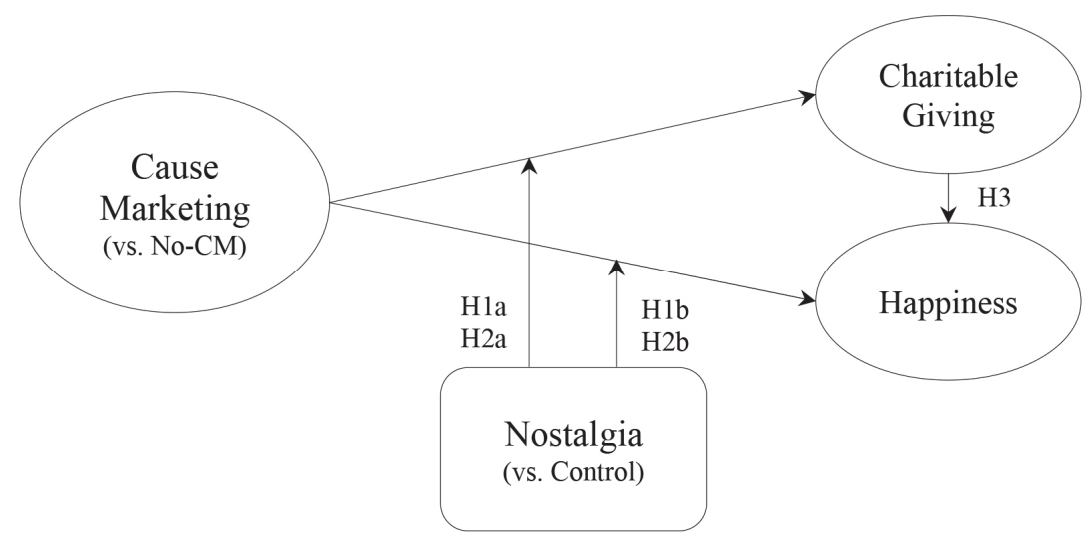

Overcoming the Cause Marketing Paradox: The Effect of Nostalgia on Charitable Giving and Happiness 7 
tend to move in the same direction. This may indicate that those dependent variables are interrelated. In line with the argument that "giving has been tied to reported states of true happiness" (Harbaugh, Mayr, \& Burghart, 2007; Thoits \& Hewitt, 2001; Liu \& Aaker, 2008, p. 543), we suggest that charitable giving has an effect on happiness, instead of the other way around. Thus, we predict that:

H3: Charitable giving has a positive effect on happiness.

\section{Methods}

\subsection{Participants and Design}

A sample of 235 students at a major university (152 females, $M_{\text {age }}=22.05$ years, age range: 18 to 40) participated in this study in return for a small gift. The experiment employed a 2 (CM vs. no-CM) x 2 (nostalgia vs. control) between-subjects design. Participants were randomly assigned to one of the four conditions.

\subsection{Procedure and Materials}

Participants read a brief scenario that exposes them to a product either linked to cause marketing or not linked to cause marketing. In this context, nostalgia was induced using a manipulation suggested by Wildschut et al. (2006, study 5; Zhou et al., 2008). Participants in the nostalgia condition read: "Bring to mind a nostalgic event in your life. Specifically, try to think of a past event that makes you feel most nostalgic. Take a few moments to think about the nostalgic event and how it makes you feel." Participants in the control condition read: "Bring to mind an ordinary event in your daily life - an event that took place in the last week. Take a few moments to think about the ordinary event and how it makes you feel." To intensify the effect of this manipulation, we asked participants to describe their specific experiences in detail so that they could more vividly reflect on the events and their feelings. Participants then listed four event-relevant keywords as the previous research conducted.

Next, participants recalled the given scenario again, assuming a hypothetical shopping situation either linked or not linked to cause marketing. Participants had to recollect any one item for themselves and then to describe the reason for choosing the particular product. After reading the scenarios, participants responded to a manipulation check (Wildschut et al., 2006) assessing their feelings of nostalgia: "Right now, I am feeling quite nostalgic" and "Right now, I am having nostalgic feelings" (7-point scales; 1 = strongly disagree, 7 = strongly agree; $a=.94)$. 
After the manipulation check, participants read a description of a nonprofit organization that supports low-income children. This fictitious organization was named "The Dream Growing Class," and the brief description explained that the mission of this foundation is to sponsor young students in low-income families. Based on the questionnaire from Zhou et al. (2008), participants were asked to indicate how much money they would donate to this charity (in Korean currency) and how many hours they would volunteer as a teacher for this charity's after school class. In addition, participants rated their happiness with the item adapted from Krishna (2011): "After making the decisions that you did, how happy do you feel?" (7-point scale; 1 = not happy at all, 7 = very happy).

Finally, we measured nostalgia proneness to investigate the potential role of individual differences. Participants completed the Southampton Nostalgia Scale (SNS; Routledge, Arndt, Sedikides, \& Wildschut, 2008), which consists of five items (one reversed scored). The measures were as follows: (1) "How often do you experience nostalgia?" (2) "How prone are you to feeling nostalgic?" (3) "Generally speaking, how often do you bring to mind nostalgic experiences?" (4) "Specifically, how often do you bring to mind nostalgic experiences? $(\mathrm{R})$ " and (5) "How important is it for you to bring to mind nostalgic experiences?" (7-point scales; $a=.88$ ). After all, participants identified their gender and age.

\section{Results}

\subsection{Manipulation Check}

A one-way ANOVA on the manipulation check for nostalgia indicated that the manipulation worked as expected. First of all, the two items $(r(235)=0.88, p<.000)$ were averaged to form a single index. Participants in the nostalgia condition showed that they felt more nostalgia than those in the control condition did $(F(1,233)=131.04, p<.000$; $M_{\text {Nostalgia }}=5.58$ vs. $\left.M_{\text {Control }}=3.29\right)$. For a more rigorous test on the manipulation check, a two-way ANOVA was run on perceived nostalgia for all conditions. Again, the result revealed a significant main effect of nostalgia priming on perceived nostalgia $(F(1,231)=$ 303.96, $p<.036)$. There was no significant main effect of cause marketing on perceived nostalgia $(F(1,231)=1.27, p>.5)$ or interaction effect between $\mathrm{CM}$ and nostalgia priming on perceived nostalgia $(F(1,231)=$ $0.43, p>.5)$.

\subsection{Charitable Giving}

The items assessing donations for time and money would function as formative indicators 
(Bagozzi \& Yi, 2012). We made a single index of charitable giving as in the study of Zhou et al. (2008). We first standardized both time and money scores into $z^{-}$-scores and then averaged them. This study employed the PROCESS macro (Hayes, 2012; Model 1, 5,000 resamples) to test our hypotheses. In the model, the presence of cause marketing $(\mathrm{CM}=1$, no-CM = 0) was the independent variable, the presence of nostalgia (nostalgia $=1$, control $=0$ ) was the moderator, and charitable giving was the dependent variable. The result showed that the interaction effect of cause marketing and nostalgia on charitable giving was significant $(\beta=0.40 ; t(231)=2.07, p<.04)$. For a better understanding of this interaction, we examined the conditional effect of cause marketing on charitable giving by the presence of nostalgia. Particularly, in the control condition, cause marketing leads to lower charitable giving than no-cause marketing does $\left(M_{\mathrm{CM} / \text { Control }}=\right.$ -0.24 vs. $M_{\text {No-CM}} /$ Control $\left.=-0.03\right)$, replicating the previous research (Krishna, 2011). However, in the nostalgia condition, cause marketing leads to greater charitable giving than no-cause marketing $\left(M_{\mathrm{CM} / \text { Nostalgia }}=0.22\right.$ vs. $M_{\text {No-CM/Nostalgia }}$ $=0.03)$, showing the reverse pattern compared to the previous literature (Krishna, 2011). The finding supports hypothesis 1a and hypothesis $2 \mathrm{a}$, indicating that there is a significant interaction effect of cause marketing and nostalgia on charitable giving (see Figure 2).

\subsection{Happiness}

We also predicted that cause marketing would have a positive effect on happiness under the nostalgia condition. We tested this hypothesis using the PROCESS macro (Hayes, 2012; Model 1, 5,000 resamples), with the

〈Figure 2〉 The effects of cause marketing and nostalgia on charitable giving

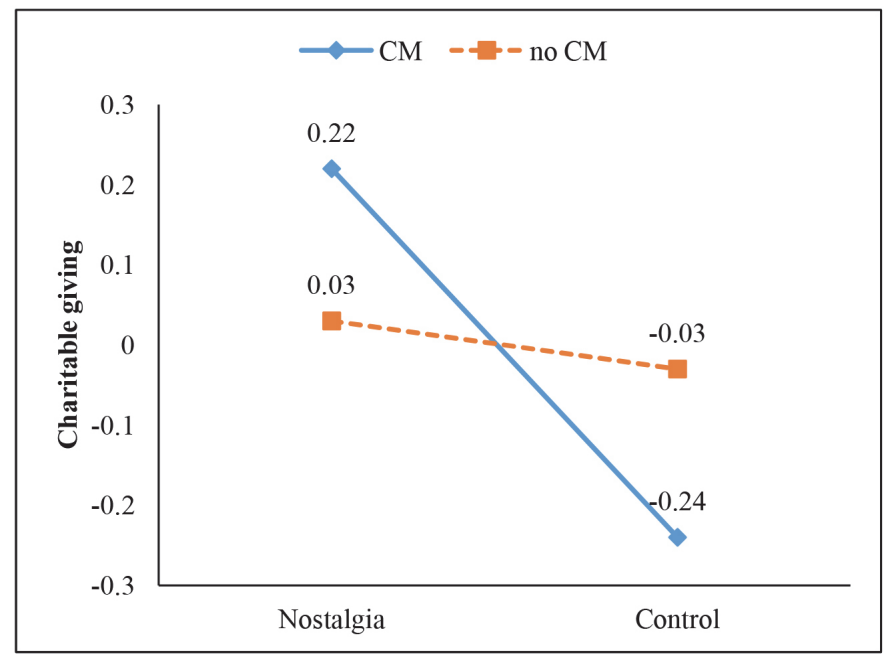


presence of cause marketing $(\mathrm{CM}=1$, no-CM $=0$ ) as the independent variable, the presence of nostalgia (nostalgia $=1$, control $=0)$ as the moderator, and feeling of happiness as the dependent variable. The result revealed that the interaction effect of cause marketing and nostalgia on happiness was significant $(\beta=1.36 ; t(231)=3.62, p<$ $.000)$. In addition, we looked into the conditional effect of cause marketing on happiness by the presence of nostalgic feeling. Specifically, for the control condition, cause marketing leads to lower happiness after the donation than no-cause marketing $\left(M_{\mathrm{CM} / \text { Control }}=5.27\right.$ vs. $M_{\mathrm{No}-\mathrm{CM} / \text { Control }}$ $=6.09$ ), indicating the same result as in the prior research (Krishna, 2011). In contrast, under the nostalgia condition, cause marketing leads to greater happiness through charity giving $\left(M_{\mathrm{CM} / \text { Nostalgia }}=6.75\right.$ vs. $M_{\mathrm{No}-\mathrm{CM} / \text { Nostalgia }}$
= 6.21) than no-cause marketing, again illustrating the reverse effect. The result supports hypothesis $1 \mathrm{~b}$ and hypothesis $2 \mathrm{~b}$, suggesting a significant interaction effect of cause marketing and nostalgia on happiness (see Figure 3).

\subsection{Charitable Giving to Happiness}

Although we originally assumed charitable giving and happiness as two dependent variables, it is reasonable to postulate that those two variables might affect each other. To identify the relationship between charitable giving and happiness, we performed a mediated moderation analysis using the PROCESS macro (Hayes, 2012; Model 8, 5,000 resamples), with the presence of cause marketing as the independent variable, the presence of nostalgia as the first-stage moderator, charitable giving

〈Figure 3〉 The effects of cause marketing and nostalgia on happiness

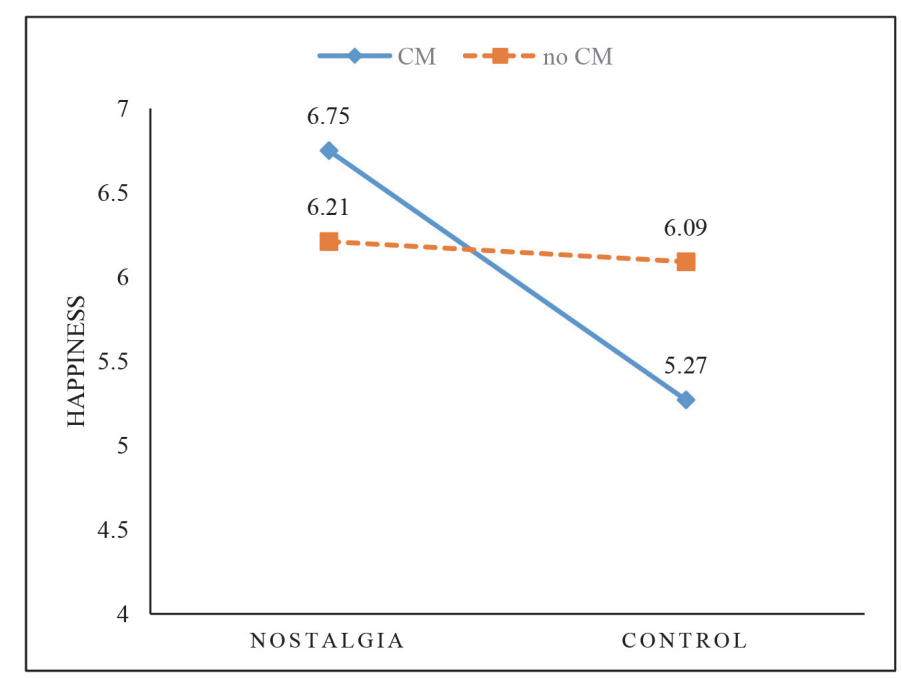

Overcoming the Cause Marketing Paradox: The Effect of Nostalgia on Charitable Giving and Happiness 11 
as the mediator, and feeling of happiness as the dependent variable. Providing support for this mediated moderation model, cause marketing and nostalgia had a significant interaction effect on charitable giving ( $\beta=0.40 ; t(231)$ $=2.07, p<.040)$. In turn, charitable giving had a significant effect on happiness $(\beta=$ $0.38 ; t(231)=3.30, p<.001)$, while the cause marketing and nostalgia interaction also predicted happiness $(\beta=1.21 ; t(231)=3.27$, $p<.001)$. Finally, the index of moderated mediation did not include zero, confirming a significant mediation through this path $(\beta=$ 0.15; 95\% CI $=0.02$ to 0.37 ). Hence, we can conclude that cause marketing has an indirect effect on happiness via charitable giving, supporting the previous argument that people view charity as a means of enhancing happiness (Liu \& Aaker, 2008). Therefore, results supported hypothesis 3 that charitable giving has a positive effect on happiness (see Figure 4).

\subsection{The Role of Nostalgia Proneness}

In order to investigate the role of individual differences in chronic nostalgia proneness, we asked participants to complete the Southampton Nostalgia Scale (SNS; Routledge et al., 2008). We ran the PROCESS macro (Hayes, 2012; Model 1, 5,000 resamples), with the presence of cause marketing as the independent variable, the presence of nostalgia as the moderator, charitable giving and happiness as the dependent variables, and nostalgia proneness as the

〈Figure 4〉 The path model for cause marketing, nostalgia, charitable giving, and happiness

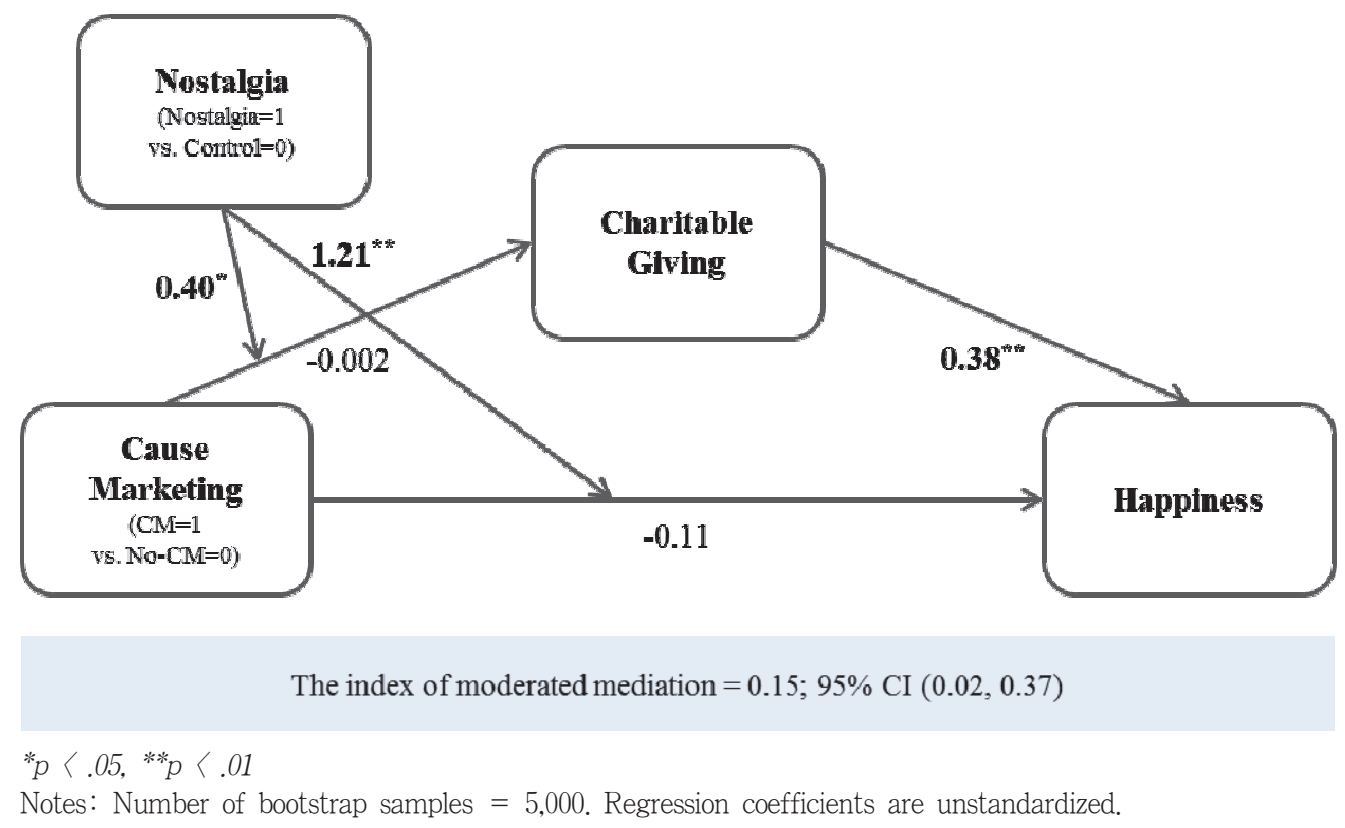

12 ASIA MARKETING JOURNAL Vol. 19 No. 03 October 2017 
covariate. First, nostalgia proneness has a significant effect on charitable giving ( $\beta=$ $0.09 ; t(230)=2.33, p<.021)$, and the interaction effect of cause marketing and nostalgia on charitable giving was still significant after controlling for nostalgia proneness $(\beta=0.49$; $t(230)=2.57, p<.011 ; M_{\mathrm{CM} / \text { Nostalgia }}=0.24 \mathrm{vs}$. $M_{\mathrm{No}-\mathrm{CM} / \text { Nostalgia }}=-0.03$ vs. $M_{\mathrm{CM} / \text { Control }}=-0.25$ vs. $\left.M_{\text {No-CM/Control }}=-0.03\right)$. That is, nostalgia proneness can increase charitable giving, as well as situational priming of the nostalgic event. However, in terms of happiness, nostalgia proneness has no significant effect on happiness $(\beta=0.09 ; t(230)=1.11, p>.3)$ while the interaction effect of cause marketing and nostalgia on happiness was statistically significant $\left(\beta=1.43 ; t(230)=3.78, p<.000 ; M_{\mathrm{CM} / \text { Nostalgia }}\right.$ $=6.77$ vs. $M_{\mathrm{No}-\mathrm{CM} / \text { Nostalgia }}=6.18$ vs. $M_{\mathrm{CM} / \text { Control }}=$ 5.26 vs. $\left.M_{\text {No-CM} / \text { Control }}=6.10\right)$. This result means that nostalgia proneness per se cannot increase happiness. In other words, nostalgia proneness as an individual difference cannot be a powerful driver for increasing charitable giving and happiness. Rather, the effects of situational priming of nostalgic feelings were sufficiently strong enough to promote charitable giving and happiness in the donation context.

\section{Discussion}

This research demonstrates that cause marketing can increase charitable giving when one's nostalgic event is primed. This work provides theoretical implications in several areas. First, the current research is contrary to the cause marketing paradox predicting that cause marketing reduces consumers' charitable giving and happiness. By identifying the situation when cause marketing enhances charitable giving, this research challenges the dominance of the cause marketing paradox. That is, this study expands the scope of prior research by providing a novel perspective that contradicts the common belief in the cause marketing literature and the licensing effect. Second, this research enriches the nostalgia charity giving literature by linking with cause marketing. According to the prior investigations, cause marketing triggers selfish motivation unlike direct donation or philanthropy (Krishna, 2011). However, we find that when prosocial behavior is encouraged by inducing nostalgia, using CM products can promote subsequent donations. Moreover, this research identifies that increased charitable giving enhances happiness ultimately. In all these processes, we also examine the role of nostalgia proneness in the context of situationally induced nostalgia.

In addition to the theoretical contributions, the present study would have managerial implications for corporate social responsibility (CSR). First, marketing managers should carefully select products for cause marketing. In line with previous findings, the current 
research corroborates that supporting a cause through the purchase of contemporary products diminishes subsequent charitable intentions and happiness. On the other hand, supporting a cause through the purchase of nostalgic products could enhance overall charitable giving and thus donors' happiness. Therefore, marketers need to elaborate their cause marketing strategies by using retrospective items that make consumers reminiscent of the past.

Second, we found that the impact of situationally primed nostalgia on charitable giving was greater than that of chronic nostalgia proneness. This implies that there is a great deal of room for marketers to draw out consumers' responses in certain contexts. Therefore, they should dissolve nostalgia into the CM products to encourage the charity donation, thereby enhancing the donors' happiness. As a memory marker that vividly and constantly reminds one of the valued past, a nostalgic product can promote altruistic behavior by making consumers engaged in memories beyond the simple possession of the product.

The current research has some limitations and opportunities for future research. For instance, it did not directly examine the mechanism underlying the interaction effect of cause marketing and nostalgia. This interaction effect may be explained with the following logic. Cause marketing with nostalgia priming renders the product with a nostalgic characteristic, and this nostalgic product functions as a memory marker that assists in making nostalgic moments more vivid in comparison with the situation of buying nothing or buying a contemporary product. It would be interesting if we can substantiate the exact mechanism.

Future research may investigate the role of nostalgic narratives. The content of the nostalgic episode may be related to the charity target or not. In the experiment, we suggested a nonprofit organization for low-income children as the target charity, expecting that the organization's nature would match participants' nostalgic episodes. Since we recruited participants from a university, most of them were in their early twenties, meaning that they were easy to bring up childhood memories as a nostalgic event. Therefore, we postulated a general case covering the match between the content of the nostalgic episode and the target charity, and thus the result was clear and converged into one conclusion. However, several questions may arise. First, if the content of the nostalgic episode is not congruent with the target charity, will the nostalgic engagement still lead to greater donations toward the non-matching target? If not, does it do only when the nostalgic recollection is linked to a specific charity? Second, does it matter whether nostalgia is induced by one's real and experienced events (i.e., personal nostalgia) or by yet-to-beexperienced cues (i.e., vicarious nostalgia)? One may wonder whether nostalgic memories never experienced but merely shared with 
contemporaries would have the same effects as real and experienced memories in the donation context. Answers to these research questions would bring useful implications.

Lastly, we collected data from young college students, who are relatively less sensitive to nostalgia. We took this step in order to induce the effect of nostalgia through situational priming only and thereby to obtain conservative results. Davis (1979) report that older people tend to be nostalgic. Batcho (1995) note that, as part of the normal aging process, nostalgia is closely related to life stage, with individuals in the later life stage feeling greater levels of nostalgia. Hence, we cautiously predict that our findings would also exist or be even more powerful among older people. Future research could confirm this prediction by recruiting participants in various ages.

〈Received June 29. 2017〉 〈Accepted October 27. 2017〉

\section{References}

Ahn, H.-K., Liu, M. W., \& Soman, D. (2009). Memory markers: How consumers recall the duration of experiences. Journal of Consumer Psychology, 19(3), 508-516.

Bagozzi, R.P., \& Yi, Y. (2012). Specification, estimation, and interpretation of structural equation models. Journal of the Academy of Marketing Science, 40(1), 8-34.

Batcho, K. I. (1995). Nostalgia: A psychological perspective. Perceptual and Motor Skills, 80(1), 131-143.

Batson, C. D. (1987). Prosocial motivation: Is it ever truly altruistic? Advances in Experimental Social Psychology, 20, 65122.

Batson, C. D., \& Shaw, L. L. (1991). Evidence for altruism: Toward a pluralism of prosocial motives. Psychological Inquiry, 2(2), 107122.

Baumeister, R. F., \& Leary, M. R. (1995). The need to belong: Desire for interpersonal attachments as a fundamental human motivation. Psychological Bulletin, 117(3), 497-529.

Cialdini, R. B., Schaller, M., Houlihan, D., Arps, K., Fultz, J., \& Beaman, A. L. (1987). Empathy-based helping: Is it selflessly or selfishly motivated? Journal of Personality and Social Psychology, 52(4), 749-758.

Davis, F. (1979). Yearning for yesterday: A sociology of nostalgia: Free Press.

Dunn, E. W., Aknin, L. B., \& Norton, M. I. (2008). Spending money on others promotes happiness. Science, 319(5870), 1687-1688. Flaherty, K., \& Diamond, W. (1999). The impact of consumer's mental budgeting on the effectiveness of cause-related marketing. Paper presented at the American Marketing Association. Conference Proceedings.

Harbaugh, W. T., Mayr, U., \& Burghart, D. R. 
(2007). Neural responses to taxation and voluntary giving reveal motives for charitable donations. Science, 316(5831), 1622-1625.

Hayes, A. F. (2012). PROCESS: A versatile computational tool for observed variable mediation, moderation, and conditional process modeling. [White paper]. Retrieved from http://www.afhayes.com.

Holak, S. L., \& Havlena, W. J. (1992). Nostalgia: An exploratory study of themes and emotions in the nostalgic experience. Advances in Consumer Research, 19, 380387.

Holbrook, M. B., \& Schindler, R. M. (1991). Echoes of the dear departed past: Some work in progress on nostalgia. Advances in Consumer Research, 18, 330-333.

Holbrook, M. B., \& Schindler, R. M. (2003). Nostalgic bonding: Exploring the role of nostalgia in the consumption experience. Journal of Consumer Behaviour, 3(2), 107-127.

Khan, U., \& Dhar, R. (2006). Licensing effect in consumer choice. Journal of Marketing Research, 43(2), 259-266.

Krishna, A. (2011). Can supporting a cause decrease donations and happiness? The cause marketing paradox. Journal of Consumer Psychology, 21(3), 338-345.

Kundera, M. (1999). Immortality: Harper Collins. Lasaleta, J. D., Sedikides, C., \& Vohs, K. D. (2014). Nostalgia weakens the desire for money. Journal of Consumer Research, 41

$$
\text { (3), 713-729. }
$$

Leary, M. R., \& Baumeister, R. F. (2000). The nature and function of self-esteem: Sociometer theory. Advances in Experimental Social Psychology, 32, 1-62.

Lichtenstein, D. R., Drumwright, M. E., \& Braig, B. M. (2004). The effect of corporate social responsibility on customer donations to corporate-supported nonprofits. Journal of Marketing, 68(4), 16-32.

Liu, W., \& Aaker, J. (2008). The happiness of giving: The time-ask effect. Journal of Consumer Research, 35(3), 543-557.

Loveland, K. E., Smeesters, D., \& Mandel, N. (2010). Still preoccupied with 1995: The need to belong and preference for nostalgic products. Journal of Consumer Research, 37(3), 393-408.

Mazar, N., \& Zhong, C.-B. (2010). Do green products make us better people? Psychological Science, 21(4), 494-498.

Mikulincer, M., Florian, V., \& Hirschberger, G. (2003). The existential function of close relationships: Introducing death into the science of love. Personality and Social Psychology Review, 7(1), 20-40.

Mikulincer, M., Shaver, P. R., Gillath, O., \& Nitzberg, R. A. (2005). Attachment, caregiving, and altruism: Boosting attachment security increases compassion and helping. Journal of Personality and Social Psychology, 89 (5), 817-839.

Robinson, S. R., Irmak, C., \& Jayachandran, S. 
(2012). Choice of cause in cause-related marketing. Journal of Marketing, 76(4), 126-139.

Routledge, C., Arndt, J., Sedikides, C., \& Wildschut, T. (2008). A blast from the past: The terror management function of nostalgia. Journal of Experimental Social Psychology, 44(1), 132-140.

Sachdeva, S., Iliev, R., \& Medin, D. L. (2009). Sinning saints and saintly sinners the paradox of moral self-regulation. Psychological Science, 20(4), 523-528.

Sedikides, C., Wildschut, T., Arndt, J., \& Routledge, C. (2006). Affect and the self. Affect in Social Thinking and Behavior: Frontiers in Social Psychology, 197-215.

Sedikides, C., Wildschut, T., \& Baden, D. (2004). Conceptual issues and existential functions. Handbook of Experimental Existential Psychology, New York: Guilford, 200-214. Seehusen, J., Cordaro, F., Wildschut, T., Sedikides, C., Routledge, C., Blackhart, G. C., .. . Vingerhoets, A. J. (2013). Individual differences in nostalgia proneness: The integrating role of the need to belong. Personality and Individual Differences, 55
(8), 904-908.

Stephan, E., Wildschut, T., Sedikides, C., Zhou, X., He, W., Routledge, C., . . Vingerhoets, A. J. (2014). The mnemonic mover: Nostalgia regulates avoidance and approach motivation. Emotion, 14(3), 545-561.

Thoits, P. A., \& Hewitt, L. N. (2001). Volunteer work and well-being. Journal of Health and Social Behavior, 42, 115-131.

Varadarajan, P. R., \& Menon, A. (1988). Causerelated marketing: A coalignment of marketing strategy and corporate philanthropy. Journal of Marketing, 52(3), 58-74.

Wildschut, T., Sedikides, C., Arndt, J., \& Routledge, C. (2006). Nostalgia: Content, triggers, functions. Journal of Personality and Social Psychology, 91(5), 975-993.

Zhou, X., Sedikides, C., Wildschut, T., \& Gao, D.-G. (2008). Counteracting loneliness on the restorative function of nostalgia. Psychological Science, 19(10), 1023-1029. Zhou, X., Wildschut, T., Sedikides, C., Shi, K., \& Feng, C. (2011). Nostalgia: The gift that keeps on giving. Journal of Consumer Research, 39(1), 39-50. 